\title{
Designing a Multi Agent System Architecture for IT Governance Platform
}

\author{
S. ELHASNAOUI, H. MEDROMI, S.FARIS, H.IGUER, A. SAYOUTI \\ (EAS- LISER) Systems Architecture Team \\ ENSEM, Hassan II University \\ BP.8118, Oasis Casablanca
}

\begin{abstract}
This paper presents a multi-agents architecture which facilitates the integration of three major IT governance frameworks: COBIT5, ITIL V3 and ISO/IEC27002, to optimize the construction of a distributed system. This architecture proposes a new and easier method to develop a distributed multi agents system, where agents involved in this system can communicate in a distributed way thanks to functionalities offered by the system. It gives finally an overview of implementation of a prototype of the proposed solution limited for the moment to integration of processes most used in the majority of information systems.
\end{abstract}

Keywords-IT Governance; Multi Agent System; COBIT 5; ITIL V3; ISO/IEC 27001/27001; Process; Information System Introduction

\section{INTODUCTION}

Governance ensures that enterprise objectives are achieved by evaluating stakeholder needs, conditions and options; setting direction through prioritization and decision making; and monitoring performance, compliance and progress against agreed-on direction and objectives [1].

There are several methodologies, standards, frameworks and good practices for Governance of information system. The most applicable and used today are ISO/IEC 27002, COBIT and ITIL [2]. Each has its positive aspects and its limitations. As a result, this paper aims to combine the three major frameworks for IT governance: ISO / IEC 27002, COBIT and ITIL in a comprehensive manner and propose an IT governance structure that covers broader aspects and supports all the needs of the organizations for more efficient IT management.

This paper describes a multi-agents architecture based on three major IT governance frameworks which are COBIT 5, ITIL V3 and ISO/IEC 27002. One of the most characteristics is the use of intelligent agents as the main components which focus on distributing the majority of the system's functionalities into processes [3].

We focused our multi-agents system architecture for IT governance by configuring our paper with the following parts: abstract of paper, brief introduction of technically requirements, fundamental aspects of state of the art which gives an idea about the theme of IT governance and the three major frameworks: COBIT 5, ITIL V3 and ISO/IEC27002, then we present an overview of multi agents system architecture and agents aspects, after that we present an IT
Governance prototype which integrate some governance processes, finally a conclusion for this paper and references.

\section{IT GOVERNANCE AND FRAMEWORKS OF GOOD PRACTICES}

\section{A. What is IT Governance?}

Governance of information systems is an expression frequently used today in the world of management information technology [4] [5]. In fact, until we heard about the governance in administrative and policy areas but not in the computer world [6]. The word is obviously subject to multiple uses. In its broadest sense, governance can sign a way to direct; to manage or control [7].

IT governance corresponds to the implementation of tools which stakeholders consider it in the operation of the information system (IS) [8] [9]. IT governance aims to define the objectives of the information system in order to plan, define and implement processes related to the management of the lifecycle of the IS [10].

These activities are based on the control and performance measurement of these processes [11]. The famous organization ISACA (Information Systems Audit and Control Association) who gives a lot of interest in the governance field defines five main axis:

- $\quad$ Strategic Alignment

- Value Creation

- $\quad$ Risk Management

- Resource Management

- Performance measurement.

\section{B. Frameworks}

IT department has recourse to good practice's guidelines: Production with ITIL, governance with COBIT, security with ISO 27000, project management with PMBOK ... [12]. These standards promote broadcasting of good practices in the company, continuous improvement, homogeneity of the process and contributing to the professionalization of the services delivery [13] [14].

1) $\operatorname{COBIT} 5$

COBIT (Control Objectives for Information Business year related Technology) is a methodology for evaluating IT 
services in the company [15]. This approach is based on an association of 37 processes (best practices collected from experts SI) and on objective indicators (KGI) and (KPIs), to put the process under control in order to provide data for the company to achieve its objectives (alignment of technology on business strategy).

This is a control framework that aims to manage risks (security, reliability, compliance) and investment. [16] It does not provide guidance or recommendations to technical (technological choices, consolidation, crisis management ...). In other words, COBIT focuses on what the company needs to do, not how it should do."

\section{2) ITIL V3}

ITIL [5] is an acronym for "Information Technology Infrastructure Library" ( IT Infrastructure Library ).

ITIL Version 3 describes the service as an organization of human resources and IT (hardware and software), whose objective is the provision of value for the company and the beneficiary of the service . [17]

ITIL provides an IT organization:

- Show that IT delivers value to the enterprise;

- Identify the business needs of the company and adapt IT to these needs and not the reverse ;

- Do not lose sight of the intake value that can have computers ;

- Focus on Quality of IT service;

- Improve the perception of IT services by customers / users ;

- Ensure the sustainability and development of the company.

ITIL Version 3 is interested in service throughout: the genesis of service to its end of life . [18] Five groups of activities have been identified:

- Service Strategy: Align IT strategy on business strategy, ensuring that the input value will enable the company to achieve its objectives .

- Service Design: Design Services from requirements collected by the Service Strategy .

- Service Transition: Ensuring the quality of the transition of a new service between studies and operations.

- Service Operation: Operate services effectively and efficiently .

- Continual Service Improvement : Creating conditions for continuous improvement of services .

3) ISO/IEC 27001/27002

ISO / IEC 27001 describes a process approach for establishing an ISMS ( system safety management information system ). But if it sets the goal, it does not state specifically how it should achieve [19]. ISO 27002 presents a series of practical recommendations, addressing both technical and organizational aspects .

The standard defines a code of good practice for use by those responsible for implementing or maintaining a management system for information security. The information security is defined as " the preservation of confidentiality, integrity and availability of information" [20] .

The standard offers 11 major fields of security using 133 security objectives ( controls ):

- Security Policy Information

- Organization of information security

- Asset Management

- Security related to human resources

- physical and environmental safeties

- Operation and Communications Management

- Access Control

- Acquisition, development and maintenance of information systems

- Incident Management

- Management Business Continuity

- Compliance.

III. Overview of Multi Agents System ArChitecture FOR IT GOVERNANCE

\section{A. Problematic}

The responsible of information systems is facing a problem of IT governance due to blooming standards of good practice, there are those who want comprehensive, dealing with all areas of activity of IS without quite detailed, and those who treat a particular area in detail without a global view. Each share of particular concern: security, quality, customer services, auditing, project development, etc...

It is a necessary evil to recognize that each function in its own practices. Simultaneously raises the question of the establishment of a global, single framework for the IT department, which meets all expectations.

It's in this perspective that this work was done, the idea is to design a platform able to integrate three major IT governance frameworks which are COBIT 5, ITIL V3 and ISO/IEC 27002, using intelligent agents as the main components which focus on distributing the majority of the system's functionalities into processes.

\section{B. The Multi-agent system}

We conducted several studies to identify the best needs of the platform, and meet the expectations of users. The Modeling of the platform is based on the principle of SMA which is everyone must cooperate to achieve the same goal. For this reason, the architecture is composed of a set of different agents which communicate and cooperate with them in an intelligent manner. 
1) What is an agent?

An agent is an entity (physical or abstract), characterized by the fact that it is autonomous in decision making, by his knowledge of itself and others, and its ability to act [21] [22] .

Experts in multi-agent systems have classified agents into three major categories according to an essential criteria that is the representation of its environment, these agents are: Reagents agents, Cognitive agents and Hybrid agents.

2) What is a multi agent system

A multi-agent system(MAS) is a distributed system consisting of a set of entities (programs)-relatively independent agents, each with their own thread, specific to fulfill goals, and ways to communicate and negotiate with other to accomplish their goal [23] [24].

MAS are ideally designed as a set of agents interacting in the cooperation, competition and coexistence manner.

Multi agents systems is a system composed of the following elements:

- An environment with a metric in general.

- A set of objects, which can associate a position in an environment in a given time. Agents can perceive, create, destroy and modify these objects.

- A set of agents, which represents the active entities of the system,

- A set of relationships between agents between them [25] [26].

- A set of operators that allow agents to perceive, produce, consume, transform and manipulate objects.

3) Contribution of MAS

The Multi-agent approach is justified by:

- Adaptation to reality

- Cooperation,

- The resolution of complex problems,

- Integration of incomplete expertise,

- Modularity,

- Efficiency,

- Reliability,

- Reuse.

\section{IT Governance architecture based on MAS}

The proposed model is a modular multi-agents architecture where all components are managed and controlled by different types of agents which are able to cooperate, propose solutions on very dynamic environments and face real problems.

There are different kinds of agents in the architecture, each one with specific roles, capabilities and characteristics. This fact facilitates the flexibility of the architecture in incorporating new agents.

As can be seen on Figure 3, the architecture defines three basic blocks which provide all functionalities of the architecture.

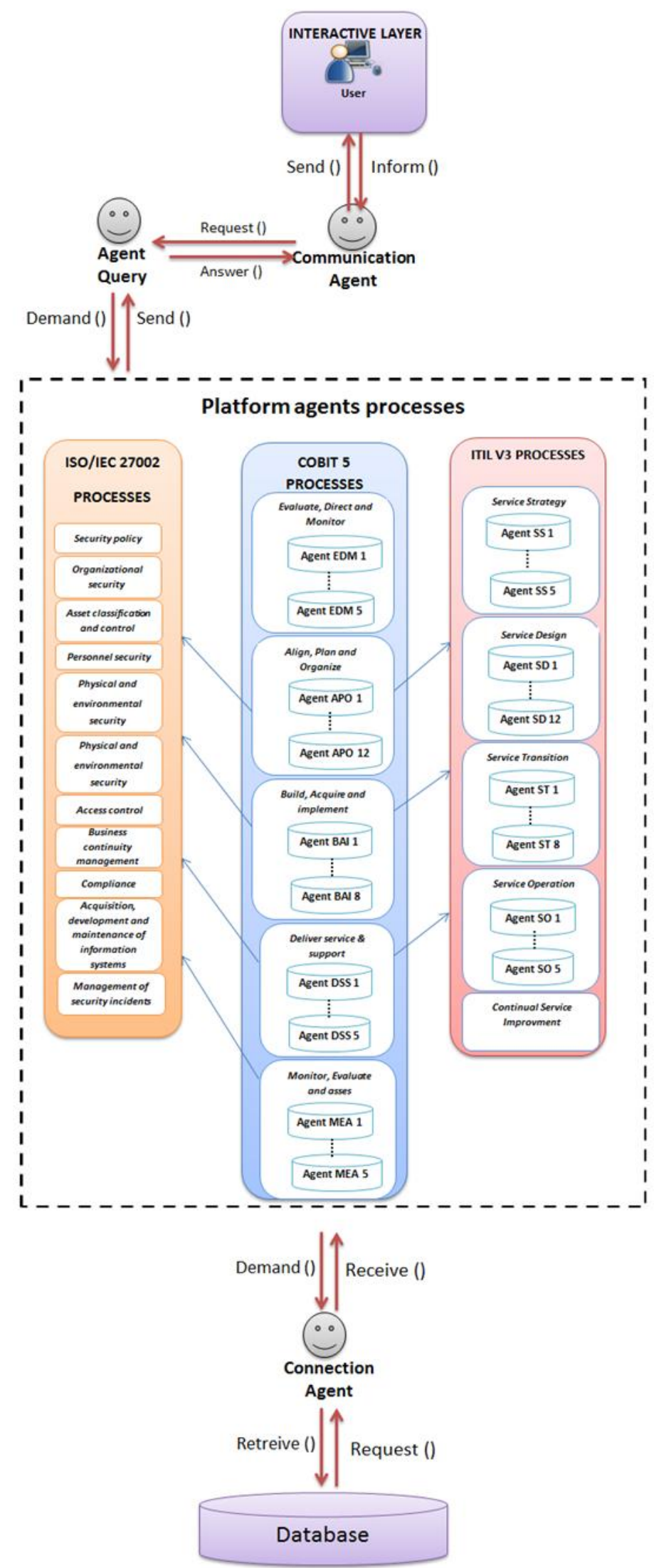

Fig. 1. The proposed multi-agent system model. 


\section{4) INTERFACE LAYER:}

This represents all the users that can use to exploit the system functionalities.

5) AGENTS PLATFORM:

This is the core of this architecture, integrating a set of agents, each one with special characteristics and behavior. These are agents participating in the functioning of the system:

a) Communication Agent: This agent is responsible for all communications between users and the platform. It manages the incoming requests from users to be managed by Agent Query. And send answers to Interface Layer.

b) Agent Query: This agent receives requests from communication agent and decides which agent process must be called by taking into account the request of users. Users can explicitly invoke a process, or can let the Agent Query decide which process from which framework is best to accomplish the requested task.

c) Agent's Processes: These agents manage the list of processes that can be used by the system; they represent processes of the three integrated frameworks: COBIT 5, ITIL $V 3$ and ISO/IEC 27002.

d) Connection Agent: This agent manages interaction between the platform of agent's process and database of the system. It retrieves adequate data and sends it the agent process concerned.

\section{6) DATABASE:}

This part of the system includes all the data and tables used by all components of the platform, including static data, indicators related to agents, and appropriate decisions to the various scenarios of behavior to be submitted to Query Agent depending on the state of the collaboration between process agents.

\section{Presentation of The Prototype of The IT GOVERNANCE PLATFORM}

Considering the large number of processes of the three governance frameworks integrated into our platform, we conducted research to develop a prototype that takes into account processes most important and used by information systems, in order to integrate them firstly. Here below the selected process for implementing this prototype:

ITIL: incident management, problem management, change management, request fulfillment.

COBIT: risk management, management of enterprise architecture, program management, portfolio management, project management.

ISO / IEC 27002: Managing Security Policies,

In addition, our platform takes into consideration both profile management and access rights and user management.

\section{A. Software architecture}

Since our platform is a web application, we chose to adopt the MVC architecture (Model-View-Controller) which is used for interactive web-applications.
This model minimizes the coupling between business logic and data presentation to web user.

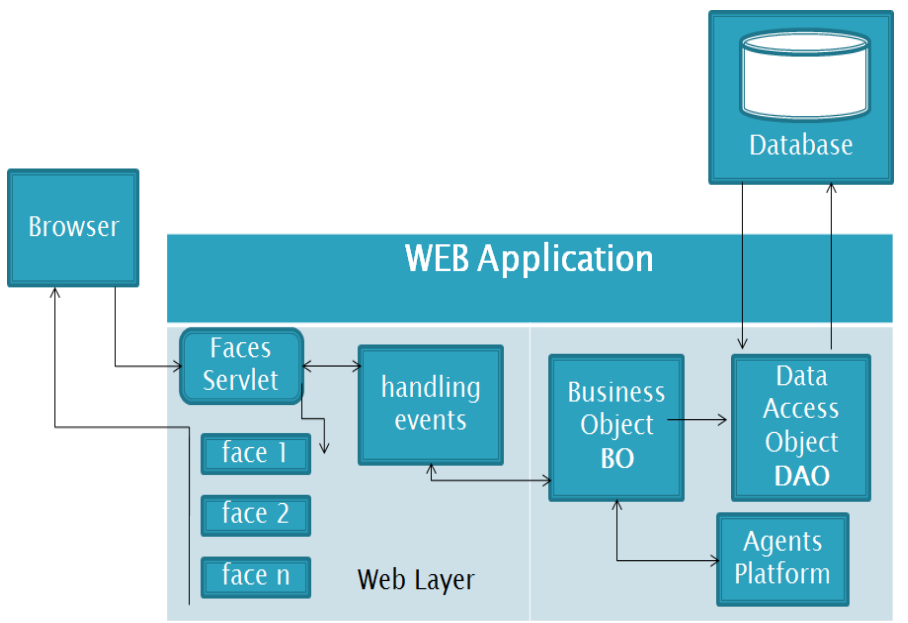

Fig. 2. Software architecture.

\section{B. Use case diagram}

Figure 3 shows use cases of the various features provided by various functionalities of the platform. All these functionalities can be managed by users after a successful authentication.

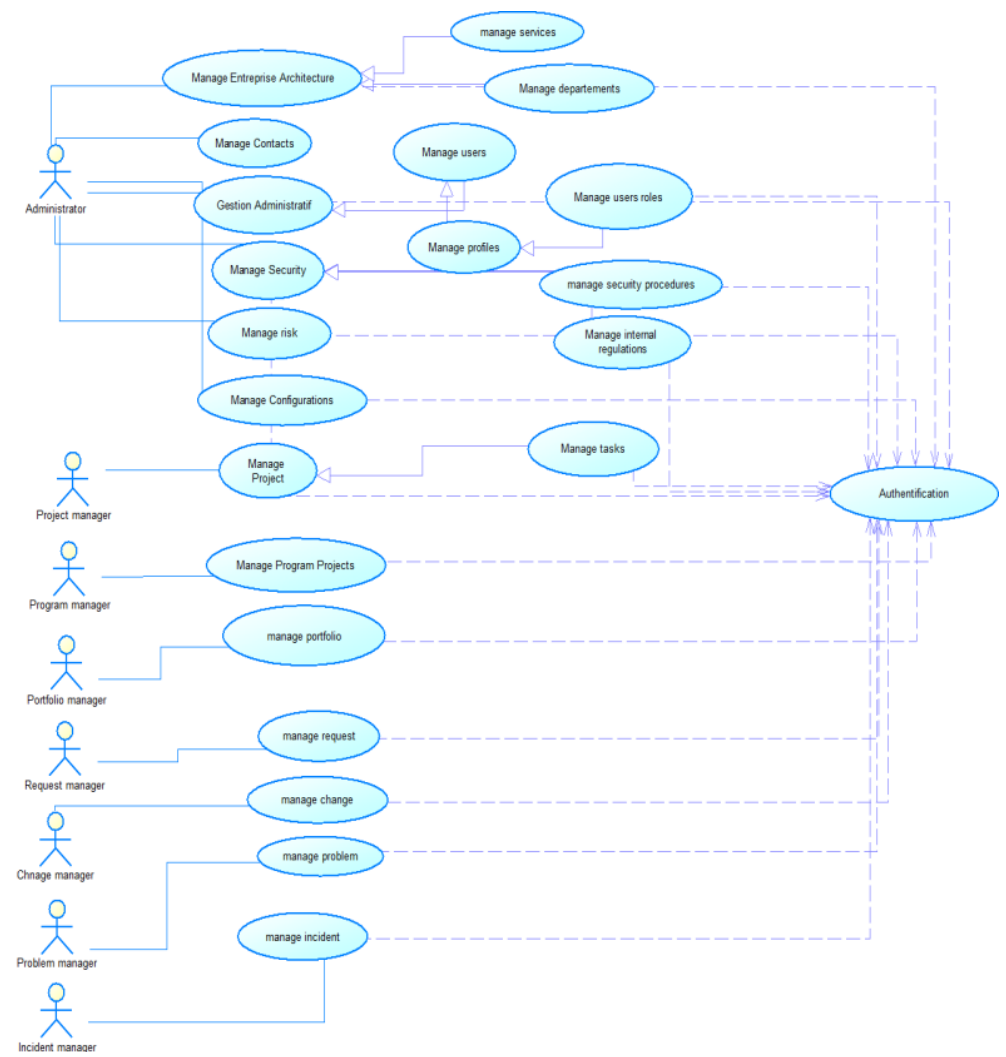

Fig. 3. Use case diagram of the prototype of IT Governance paltform.

\section{Perspectives}

Future work consists on extending our prototype by defining a detailed architecture of each agent and specifying 
communication between these agents. Our objective is to validate the architecture that we propose in this paper by developing a distributed platform that will allow companies to establish effective governance of their information system.

\section{CONCLUSION}

This article propose an architecture of IT Governance based on three major frameworks : COBIT 5, ITIL V3 and ISO/IEC 27002.

One of the most characteristics of proposed solution is the use of intelligent agents which communicate and cooperate in order to deliver answers of user's requests and to establish governance in the information system.

It briefly talked after that, about prototype of the IT Governance platform which integrate some processes from the integrated frameworks in order to validate the proposed architecture.

\section{REFERENCES}

[1] (AFAI, 2002) AFAI, ITGI, COBIT, Gouvernance, Contrôle et Audit de l'Information et des Technologies Associées, Troisième édition, 2002.

[2] (Agostinelli, 2009) S. Agostinelli, L'analyse du processus métier au coeur du système d'information oriente le projet d'intelligence économique. In, M., Ghenima, A., Ouhsel \& S., Sidhom, (eds.).

[3] SIIE"2009 : 2e Conférence Internationale Systèmes d"Information et Intelligence Economique, (pp. 254-271). Nancy : IHE éditions, 2009.

[4] (Alonso, 1997) G. Alonso, D. El Abbadi, C. Mohan, Functionality and Limitation of Current Workflow Management Systems, IEEE Expert, 1997.

[5] (Ploesser, 2008) K. Ploesser, J. Recker and M. Rosemann, Towards a Classification and Lifecycle of Business Process Change, 9th Workshop on Business Process Modeling, Development, and Support (BPMDS'08), 16-17 June 2008, Montpellier, France.

[6] (Luftman, 2004b) J. Luftman, Assessing Business-IT Alignment Maturity, in Strategies for Information Technology Governance, Ed. by Van Grembergen, Idea Group, 2004, ISBN 1591401402.

[7] (Muehlen, 2008) M. zur Muehlen, D.T. Ho, Service Process Innovation: A Case Study of BPMN in Practice. In: Ralph Sprague, Jr. (Ed.): Proceedings of the 41 st Hawaie $i$ International Conference on System Sciences. Waikoloa, HI, January 7-10, 2008.

[8] Consilium-ICT, ITIL et la gouvernance des systèmes d'informations: vers une eadministration agile, Toulouse, Juin 2009.

[9] Maico Gehrmann, "Combining ITIL, COBIT and ISO/IEC 27002 for structuring comprehensive information technology for management in organizations", Navus - Revista de Gestão eTecnologia. Florianópolis, SC, v. 2, n. 2, p. 66 - 77, jul./dez. 2012

[10] S.Elhasnaoui, H. Medromi, A. Sayouti, « Etude de mise en œuvre des solutions conformes à ITIL et modélisation de la solution proposée », JDTIC 2012.
[11] S.Elhasnaoui, H. Medromi, A. Sayouti, Multi-agents modeling platform for IT governance based on ITIL" International Conference on Engineering Education and Research, ICEER 2013.

[12] S.Elhasnaoui, H. Medromi, A. Sayouti, "Une approche multiagents pour la gouvernance des systèmes d'information basée sur le référentiel ITIL », Journées Doctorales en Systèmes d'Information, Réseaux et Télécommunication (JDSIRT 2013).

[13] J.Skiti et H.Medromi, "La Gouverance des Technologies de l'Information à base du Système Multi-agent et le référentiel COBIT". Workshop on Information Technologies and Communication, WOTIC 2011, Casablanca, Morocco.

[14] Cigref, Gouvernance du système d'information, Problématiques et démarches. (Septembre 2002).

[15] Dario Forte, "Security standardization in incident management: the ITIL approach", Volume 2007, Issue 1, January 2007, Pages 14-16.

[16] M.N. Kooper, R. Maes, E.E.O. Roos Lindgreen "On the governance of information: Introducing a new concept of governance to support the management of information". International Journal of Information Management: The Journal for Information Professio- Professionals, Volume 31 Issue 3, June, 2011, Pages 195-200

[17] Eric LELEU, « Le COBIT : L'état de l'Art, Socle de la gouvernance des SI », 2009.

[18] Patrick Stachtchenko, «COBIT 5, ses apports pour le management et la gouvernance du SI », 25 Janvier 2013.

[19] Delbrayelle, Introduction à ITIL V3 et au cycle de vie des services, juillet 2011. ISO office "Information technology - Security techniques - Code of practice for information security management", 2005.

[20] ITGI and OGC, "Aligning CobiT® 4.1, ITIL ${ }^{\circledR}$ V3 and ISO/IEC 27002 for Business Benefit" 2008.

[21] Shoham, Y. Agent-oriented programming. Artificiel Intelligence, February 1992. Stanford,USA.

[22] Weiss, G., (Ed.), Multi-agent Systems. A Modern Approach to Distributed Artificial Intelligence, The MIT Press, Cambridge, Massachusetts, 1999.

[23] Dante I. Tapia, Sara Rodríguez, Javier Bajo, Juan M. Corchado, FUSION@, A SOABased Multi-Agent Architecture

[24] Sayouti, F. Moutaouakkil, H. Medromi. "The Interaction- Oriented Approach for Modeling and Implementing Multi-Agent Systems", International Review on Computers and Software (I.RE.CO.S), Vol. 5, N. 2, Mars 2010

A.Sayouti, H. Medromi, Book Chapter in the book "Multi- AgentSystems Modeling, Control, Programming, Simulations and Applications", ISBN 978-953-307-174-9, InTech, April4, 2011.

[25] A. SAYOUTI, H. MEDROMI -"Les Systèmes Multi-Agents : Application au Contrôle sur Internet" Auteurs Éditions universitaires européennes, Août 2012.].

[26] A.SAYOUTI \& H. MEDROMI Autonomous and Intelligent Mobile Systems based on Multi-agent, Book Chapter in the book "Multi-agent Systems - Modeling Control , Programming, Simulations and Applications". 